\title{
Nasal Cartilage
}

National Cancer Institute

\section{Source}

National Cancer Institute. Nasal Cartilage. NCI Thesaurus. Code C49593.

Any of the cartilaginous structures that provide structure and support to the nose. 